\title{
Inhibitory effect of bufalin combined with Hedgehog signaling pathway inhibitors on proliferation and invasion and metastasis of liver cancer cells
}

\author{
XIA SHENG ${ }^{1}$, XIAOTING SUN ${ }^{3}$, KANG SUN $^{2}$, HUA SUI $^{3}$, JIANMIN QIN $^{2}$ and QI LI ${ }^{3}$ \\ Departments of ${ }^{1}$ Pathology, ${ }^{2}$ General Surgery, Affiliated to the Third Hospital, Second Military Medical University, Shanghai; \\ ${ }^{3}$ Department of Medical Oncology, Shuguang Hospital, Shanghai University of Traditional Chinese Medicine, Shanghai, P.R. China
}

Received May 30, 2016; Accepted July 29, 2016

DOI: $10.3892 /$ ijo.2016.3667

\begin{abstract}
Hepatocellular carcinoma (HCC) is difficult to diagnose early, resulting in only $30 \%$ resection rate. $\mathrm{HCC}$ is a relatively chemo-resistant tumor, molecular targeted therapy can only benefit approximately $30 \%$ patients with liver cancer. Bufalin $(\mathrm{Bu})$ is one of the topoisomerase II inhibitors, many studies have recently focused on the anticancer activities of bufalin. In the present study, we report that bufalin can inhibit the proliferation, invasion and metastasis of liver cancer cells via the Hh signaling pathway. The human high metastasis potential LM3 hepatoma cells (HCC-LM3) were cultured in vitro, bufalin and/or Hedgehog signaling pathway inhibitors (GANT61, cyclopamine) was added into cell culture fluid for $72 \mathrm{~h}$ to observe the antitumor effect of bufalin. The results showed that bufalin was able to inhibit epithelial mesenchymal transition (EMT), and extracellular matrix (ECM) degradation and angiogenesis of liver cancer cells by influencing the expression of Ptch1'Gli1'Gli3 proteins in Hh signaling pathway. Bufalin could downregulate the downstream target molecules of MMP-2, MMP-9, $\beta$-catenin and VEGF in liver cancer cells by influencing the Gli1 and Gli3 expression of $\mathrm{Hh}$ signaling pathway, and upregulate the E-cadherin expression of liver cancer cells by influencing the Gli3 expression of $\mathrm{Hh}$ signaling pathway. Therefore, the present study shows that bufalin combined with Hedgehog signaling pathway inhibitors can significantly reduce the malignant biological behavior of the liver cancer cells.
\end{abstract}

Correspondence to: Dr Jianmin Qin, Department of General Surgery, Affiliated to the Third Hospital, Second Military Medical University, Moyu North Road 700, Shanghai 201805, P.R. China E-mail: jianminqin@yahoo.com

Dr Qi Li, Department of Medical Oncology, Shuguang Hospital, Shanghai University of Traditional Chinese Medicine, Zhangheng Road 528, Shanghai 201203, P.R. China

E-mail: lzwf@hotmail.com

Key words: bufalin, proliferation, invasion, metastasis, hedgehog signaling pathway, hepatocellular carcinoma

\section{Introduction}

Hepatocellular carcinoma (HCC) is one of the most common malignancies worldwide with annual incidence of 600,000 or more, and ranked the third most important cause of cancer death, with mortality rate of $18.8 \%$ in all malignant tumors (1-4). In China, the mortality of HCC ranked second in all cancers and the number of deaths was $53 \%$ of the total number of deaths around the world, being thus the first in the world $(5,6)$. Surgical treatments, such as liver resection and transplantation, are usually the first-line therapeutic strategies for HCC. But there are many restrictive causes of liver cancer including concealed pathogenesis, rapid progress and difficulty in early diagnosis resulting in only $30 \%$ resection rate. In addition, since $\mathrm{HCC}$ is a relatively chemo-resistant tumor, systemic cytotoxic chemotherapy agents are minimally effective on improving the survival of patients with advanced HCC. Furthermore, some chemotherapy drugs have also severe toxic side-effects on the heart, liver and kidney. Molecular targeted therapy can only benefit approximately $30 \%$ of patients with liver cancer. Moreover, HCC metastasize early, and the postoperative recurrence rate can reach $40-70 \%$, it seriously affects the survival and quality of life in patients with liver cancer (7-10). Therefore, to improve the therapeutic efficacy and prolong survival of patients with liver cancer preparing new-type and low-toxic drugs against cellular proliferation, invasion and metastasis of hepatocellular carcinoma is urgent. Recently, traditional Chinese medicines and their active components have attracted a great deal of attention as candidates for HCC therapy.

Bufalin (Bu) is the major digoxin-like immunoreactive component of Chan $\mathrm{Su}$, a traditional Chinese medicine obtained from the skin and parotid venom glands of a toad. It is one of the topoisomerase II inhibitors, which has pharmacological effects such as antitumor, anti-radiation, anti-clotting, analgesia and cardiotonic efficacy $(11,12)$. Many studies have focused on the anticancer activities of bufalin, which have been proven to inhibit the proliferation and angiogenesis, induce differentiation and apoptosis, reverse the drug resistance, alter gene expression in tumor cells and regulate the body's immune system $(13,14)$. In our previous studies, it was indicated that bufalin could significantly inhibit prolifera- 
tion, invasion and metastasis of liver cancer cells by blocking cell cycle at S and G2 phase in BEL-7402 hepatoma cells, and the inhibitive efficacy was time and dose dependent (15). Yet, the effective mechanism of bufalin on inhibiting proliferation, invasion and metastasis of tumor cells is not yet clear in hepatocellular carcinoma. Hedgehog $(\mathrm{Hh})$ signaling pathway was first discovered in Drosophila mutant gene research by Wieschaus and Nusslein-Volhard C in 1980. It is a highly conservative cellular signal transduction system, which plays an important role in regulating cell growth and survival (16). It was demonstrated that Hh signaling pathway was involved in the regulation of the development process of gastric, pancreatic, liver cancer and other malignant tumors (17-19). We studied whether bufalin can inhibit the growth, invasion and metastasis of liver cancer cells by influencing the $\mathrm{Hh}$ signaling pathway. In vitro culturing the human high metastasis potential LM3 hepatoma cells (HCC-LM3), the present study explored the biological role of bufalin in inhibiting proliferation, invasion and metastasis of liver cancer cells via Hh signaling pathway.

\section{Materials and methods}

Reagents. Bufalin, purchased from Sigma Chemical Co. (St. Louis, MO, USA), was dissolved in anhydrous alcohol at a concentration of $10^{-1} \mathrm{~mol} / 1$ and stored at $4^{\circ} \mathrm{C}$. High glucose Dulbecco's modified Eage's medium (DMEM) and fetal bovine serum (FBS) were purchased from Gibco (Gaithersburg, MD, USA). The antibodies of $\beta$-actin, SHH, PTCH1, Gli1, MMP-2, E-cadherin and $\beta$-catenin were purchased from Cell Signaling Technology, Inc. (Beverly, MA, USA). Gli3 antibody was purchased from Milipore (Billerica, MA, USA). MMP-9 and VEGF antibodies were purchased from Abcam (Cambridge, (MA, USA). GANT61 (G61) and cyclopamine (cyc), the inhibitors of Hh signaling pathway, were purchased from Selleck Chemicals LLC (Houston, TX, USA). GANT61 can specifically inhibit Gli1 protein expression and cyclopamine is the specific inhibitor of Smo protein expression.

Cell lines. HCC-LM3 cells were obtained from the Liver Cancer Institute of Zhongshan Hospital Affiliated to Fudan University. The cells were cultured in high glucose DMEM supplemented with $10 \% \mathrm{FBS}, 100 \mathrm{U} / \mathrm{ml}$ of penicillin and $100 \mu \mathrm{g} / \mathrm{ml}$ of streptomycin in a humidified atmosphere with $5 \% \mathrm{CO}_{2}$ in air at $37^{\circ} \mathrm{C}$. Then, the cells in the logarithmic growth phase were collected for the following experiments.

Grouping. HCC-LM3 cells were cultured in vitro, they were divided into the control group, the bufalin group, the bufalin+GANT61 group, the bufalin+cyclopamine group and the bufalin+GANT61+cyclopamine group according to the experimental requirements.

Drug concentration. According to our previous studies (15), the $0.04 \mu \mathrm{g} / \mathrm{ml}$ of bufalin was chosen as an effective concentration. Following the manufacturer's instructions and the related experiments, the $2.148 \mu \mathrm{g} / \mathrm{ml}$ of GANT61 and the $0.412 \mu \mathrm{g} / \mathrm{ml}$ of cyclopamine were chosen as effective concentrations, respectively.
Cell proliferation assay. The Cell Counting kit-8 (Dojindo Molecular Technologies, Inc., Tokyo, Japan) assay was used to evaluate cell proliferation. Briefly, cells in the logarithmic growth phase were plated at a density of $10 \times 10^{4}$ cells $/ \mathrm{ml}$, then $100 \mu \mathrm{l} /$ well in 96-well plates. Twelve hours later, the cells were treated with various concentrations of the drugs. A total of $200 \mu \mathrm{l}$ DMEM was used to compare with other groups as the blank group, $200 \mu 1 \mathrm{DMEM}$ was injected into culture plate in the control group, $200 \mu \mathrm{l}$ bufalin was injected into culture plate in the bufalin group, $200 \mu \mathrm{l}$ bufalin and $200 \mu \mathrm{l}$ GANT61 were injected into culture plate in the bufalin+GANT61 group, $200 \mu \mathrm{l}$ bufalin and $200 \mu \mathrm{l}$ cyclopamine were injected into culture plate in the bufalin+cyclopamine group, $200 \mu \mathrm{l}$ bufalin, $200 \mu \mathrm{l}$ GANT61 and $200 \mu \mathrm{l}$ cyclopamine were injected into culture plate in the bufalin+GANT61+cyclopamine group. The final concentrations of buffalin, GANT61 and cyclopamine added to the cell culture medium for each group were 0.04 , 2.148 and $0.412 \mu \mathrm{g} / \mathrm{ml}$, respectively. After incubation for $72 \mathrm{~h}$, the CCK-8 was used to detect the cell viability following the manufacturer's instructions. Each experiment was performed in triplicate. The cell inhibition ratio was calculated by the following formula: cell inhibition ratio $(\%)=[1$ - (average absorbance of treated group - average absorbance of blank group)/(average absorbance of control group - average absorbance of blank group)] x $100 \%$.

Flow cytometry for cell cycle phase. Cell cycle analysis was performed using flow cytometry and DNA content Quantitation assay kit (Nanjing KeyGen Biotech., Co., Ltd., Nanjing, China). Cells in the logarithmic growth phase were plated at a density of $10 \times 10^{4}$ cells $/ \mathrm{ml}$, then $100 \mu \mathrm{l} /$ well in 6 -well plates. Twelve hours later, the cells were treated with various concentrations of the drugs. A total of $2 \mathrm{ml}$ of DMEM was injected into culture plate in the control group, $2 \mathrm{ml}$ bufalin was injected into culture plate in the bufalin group, $2 \mathrm{ml}$ bufalin and $2 \mathrm{ml}$ GANT61 were injected into culture plate in the bufalin+GANT61 group, $2 \mathrm{ml}$ bufalin and $2 \mathrm{ml}$ cyclopamine were injected into plate in the bufalin+cyclopamine group, $2 \mathrm{ml}$ bufalin, $2 \mathrm{ml}$ GANT61 and $2 \mathrm{ml}$ cyclopamine were injected into culture plate in the bufalin+GANT61+cyclopamine group. The final concentrations of buffalin, GANT61 and cyclopamine added to the cell culture medium for each group were $0.04,2.148$ and $0.412 \mu \mathrm{g} / \mathrm{ml}$, respectively. After treatment with different compounds for $72 \mathrm{~h}$, cells were harvested, centrifuged, washed and suspended twice with cold phosphate-buffered saline (0.1 M PBS) at $2000 \mathrm{rpm}$ for $5 \mathrm{~min}$, then fixed in $70 \%$ ethanol and stored at $4^{\circ} \mathrm{C}$ for $2 \mathrm{~h}$. Following two washes with $0.1 \mathrm{M}$ PBS, fixed cells were incubated in $100 \mu \mathrm{l}$ RNase at $37^{\circ} \mathrm{C}$ for $30 \mathrm{~min}$, followed by staining of the DNA with $400 \mu 1$ propidium iodide (PI) at $4^{\circ} \mathrm{C}$ for $30 \mathrm{~min}$ in the dark. Then, each sample was analyzed using CellQuest software (Becton-Dickinson, San Jose, CA, USA) and the percentage of cells within the G1, S and G2 phases of the cell cycle was determined. Each experiment was performed in triplicate.

Analysis of cell apoptosis. Cells in the logarithmic growth phase were plated at a density of $10 \times 10^{4}$ cells $/ \mathrm{ml}$, then, $100 \mu \mathrm{l} /$ well in 6-well plates. Twelve hours later, the cells were treated with various concentrations of all drugs. A total of $2 \mathrm{ml}$ DMEM was injected into culture plate in the 
control group, $2 \mathrm{ml}$ bufalin was injected into culture plate in the bufalin group, $2 \mathrm{ml}$ bufalin and $2 \mathrm{ml}$ GANT61 were injected into culture plate in the bufalin+GANT61 group, $2 \mathrm{ml}$ bufalin and $2 \mathrm{ml}$ cyclopamine were injected into culture plate in the bufalin+cyclopamine group, $2 \mathrm{ml}$ bufalin, $2 \mathrm{ml}$ GANT61 and $2 \mathrm{ml}$ cyclopamine were injected into culture plate in the bufalin+GANT61+cyclopamine group. The final concentrations of buffalin, GANT61 and cyclopamine added to the cell culture medium for each group were 0.04 , 2.148 and $0.412 \mu \mathrm{g} / \mathrm{ml}$, respectively. After $72 \mathrm{~h}$ of treatment with different agents, cells were harvested, centrifuged and washed twice with cold $0.1 \mathrm{M}$ PBS at $2000 \mathrm{rpm}$ for $5 \mathrm{~min}$, then suspended in $100 \mu \mathrm{l} 1 \mathrm{X}$ binding buffer. Next, cells were incubated with $5 \mu \mathrm{l}$ Annexin $\mathrm{V}$ and $5 \mu \mathrm{l} \mathrm{PI}$ for $15 \mathrm{~min}$ at $25^{\circ} \mathrm{C}$ in dark room. Finally, each sample was injected with $400 \mu \mathrm{l}$ $1 \mathrm{X}$ binding buffer, phase distributions of the cell cycle and hypodiploid DNA were determined by flow cytometry and Annexin V-FITC apoptosis detection kit I (BD Biosciences, San Jose, CA, USA). Then assessed for cell apoptosis by CellQuest software (Becton-Dickinson). Each experiment was performed in triplicate.

Analysis of cell migration and invasion. Cells in the logarithmic growth phase were plated at a density of $10 \times 10^{4}$ cells/ml, then $100 \mu \mathrm{l} /$ well in 6 -well plates. Twelve hours later, the cells were treated with various concentrations of the drugs. A total of $2 \mathrm{ml}$ DMEM was injected into culture plate in the control group, $2 \mathrm{ml}$ bufalin was injected into culture plate in the bufalin group, $2 \mathrm{ml}$ bufalin and $2 \mathrm{ml}$ GANT61 were injected into culture plate in the bufalin+GANT61 group, $2 \mathrm{ml}$ bufalin and $2 \mathrm{ml}$ cyclopamine were injected into culture plate in the bufalin+cyclopamine group, $2 \mathrm{ml}$ bufalin, $2 \mathrm{ml} \mathrm{GANT61}$ and $2 \mathrm{ml}$ cyclopamine were injected into culture plate in the bufalin+GANT61+cyclopamine group. The final concentrations of buffalin, GANT61 and cyclopamine added to the cell culture medium for each group were $0.04,2.148$ and $0.412 \mu \mathrm{g} / \mathrm{ml}$, respectively. The cell migration assay was analyzed in a Transwell permeable support system (Corning, Inc., Corning, NY, USA) containing 24-well Transwell (unit $8 \mu \mathrm{l}$ pore size polyvinylidenefluoride) filters. After $72 \mathrm{~h}$ of treatment with different agents, cells were harvested and suspended in new DMEM at a density of $1 \times 10^{6}$ cells $/ \mathrm{ml}$. Then, the colected cells were seeded into the upper chamber at $100 \mu \mathrm{l} /$ well with a serum-containing medium $(500 \mu \mathrm{l})$ simultaneously added to the lower chamber. Forty-eight hours later, the cells on the upper surface of the filter were removed with cotton swabs, and the cells invading across the Matrigel to the lower surface of the membrane were stained with Giemsa (Sigma-Aldrich, Munich, Germany) for $10 \mathrm{~min}$, the number of migrated cells was counted in five fields of each triplicate filter with an inverted microscope. Cell migration ratio $(\%)=($ the number of cell migrations in the treated group/the number of cell migrations in the control group) $\mathrm{x} 100 \%$.

The cell invasion assay was carried out similarly, except that 1:4 DMEM-diluted Matrigel (BD Biosciences, Franklin Lakes, NJ, USA) was added to each well for $24 \mathrm{~h}$ before cells were seeded onto the membrane. The number of invaded cells was counted in five fields of each triplicate filter with an inverted microscope. Cell invasion ratio $(\%)=($ the number of cell invasion in the treated group/the number of cell invasion in the control group) $\mathrm{x} 100 \%$.

Cell adhesion assay. The 96-well flat-bottomed plates were precoated with $50 \mu \mathrm{l} /$ well of 1:4 DMEM-diluted Matrigel at $4^{\circ} \mathrm{C}$ overnight. Cells in the logarithmic growth phase were plated at a density of $10 \times 10^{4}$ cells $/ \mathrm{ml}$, then $100 \mu \mathrm{l} /$ well in 6 -well plates. Twelve hours later, the cells were treated with various concentrations of the drugs. A total of $2 \mathrm{ml}$ DMEM was injected into culture plate in the control group, $2 \mathrm{ml}$ bufalin was injected into culture plate in the cufalin group, $2 \mathrm{ml}$ bufalin and 2 mlGANT61 were injected into culture plate in the bufalin+GANT61 group, $2 \mathrm{ml}$ bufalin and $2 \mathrm{ml}$ cyclopamine were injected into culture plate in the bufalin+cyclopamine group, $2 \mathrm{ml}$ bufalin, $2 \mathrm{ml}$ GANT61 and $2 \mathrm{ml}$ cyclopamine were injected into culture plate in the bufalin+GANT61+cyclopamine group. The final concentrations of buffalin, GANT61 and cyclopamine added to the cell culture medium for each group were 0.04, 2.148 and $0.412 \mu \mathrm{g} / \mathrm{ml}$, respectively. After $72 \mathrm{~h}$ of treatment with different agents, cells were harvested and suspended in new DMEM with $10 \%$ FBS at a density of $1 \times 10^{6}$ cells $/ \mathrm{ml}$. Then, the collected cells were seeded into a 96-well plate at $100 \mu \mathrm{l} /$ well, blocking at $37^{\circ} \mathrm{C}$ for $2 \mathrm{~h}$. Only $100 \mu \mathrm{l}$ of DMEM without cells was injected in each well as a blank group. The average numbers of adhered cells were counted using the CCK-8. The 96-well plate was put into enzyme-labeled instrument, and OD value was obtained by $450 \mathrm{~nm}$ wavelength detection. Each experiment was performed in triplicate. The cell adhesion ratio was calculated by the following formula: Cell adhesion ratio $(\%)=($ average OD value of treated group/average OD value of control group) $\mathrm{x} 100 \%$.

Protein expression assay with western blot technique. Cells in the logarithmic growth phase were plated at a density of $10 \times 10^{4}$ cells $/ \mathrm{ml}$, then $5 \mathrm{ml} /$ flask in cell culture flask. Twelve hours later, the cells were treated with various concentrations of the drugs. A total of $2 \mathrm{ml}$ DMEM was injected into culture flask in the control group, $2 \mathrm{ml}$ bufalin was injected into culture flask in the bufalin group, $2 \mathrm{ml}$ bufalin and $2 \mathrm{ml}$ GANT61 were injected into culture flask in the bufalin+GANT61 group, $2 \mathrm{ml}$ bufalin and $2 \mathrm{ml}$ cyclopamine were injected into culture flask in the bufalin+cyclopamine group, $2 \mathrm{ml}$ bufalin, $2 \mathrm{ml}$ GANT61 and $2 \mathrm{ml}$ cyclopamine were injected into culture flask in the bufalin+GANT61+cyclopamine group. The final concentrations of buffalin, GANT61 and cyclopamine added to the cell culture medium for each group were $0.04,2.148$ and $0.412 \mu \mathrm{g} / \mathrm{ml}$, respectively. After cultured for $72 \mathrm{~h}$, cells in various groups were, respectively, washed with ice-cold $0.01 \mathrm{M}$ PBS and extracted in protein lysis buffer (Beyotime Institute of Biotechnology, Haimen, China). Protein concentrations were assayed with the BCA protein assay kit (Beyotime Institute of Biotechnology). Protein samples of cell lysates were mixed with 5X sodium dodecyl sulfate (SDS) loading buffer (dilution 1:4), boiled for $5 \mathrm{~min}$, then separated on $10 \%$ SDS polyacrylamide gels. After electrophoresis, proteins were transferred onto polyvinylidene fluoride membranes, blocked in $5 \%$ non-fat dry milk in phosphate-buffered saline with Tween-20 (PBST) for $1 \mathrm{~h}$, and incubated with corresponding antibodies against $\beta$-actin (dilution 1:2,000), SHH (dilution 1:1,000), PTCH1 (dilution 1:1,000), Gli1 (dilution 1:1,000), Gli3 (dilu- 
tion 1:1,000), E-cadherin (dilution 1:1,000), $\beta$-catenin (dilution 1:1,000), MMP-2 (dilution 1:1,000), MMP-9 (dilution 1:5,000) and VEGF (dilution 1:2,000) overnight at $4^{\circ} \mathrm{C}$. The membranes were washed three times with PBST and incubated for $1 \mathrm{~h}$ at room temperature with a horseradish peroxidase-conjugated secondary antibody (dilution 1:1,000). After washing again three times with PBST, blots were incubated with ECL plus chemiluminescence substrate (Millipore, Billerica, MA, USA) and digital images were acquired using a ChemiDoc system employing Quantity One software (Shanghai Peiqing, Shanghai, China). Three independent blots were analyzed for each protein.

Statistical analysis. Data were analyzed using analysis of variance (SPSS 18.0 and Graphpad Prism 5; SAS Institute, Inc., Cary, NC, USA). Data are expressed as the mean values \pm standard of the mean. P-values of $<0.05$ were considered statistically significant.

\section{Results}

Bufalin inhibits proliferation of HCC-LM3 cells. The CCK-8 assay showed that the inhibitive rates of cell proliferation were $33.68 \pm 8.38,38.28 \pm 8.33,58.30 \pm 9.08$ and $72.71 \pm 7.13 \%$ in the bufalin group, the bufalin+GANT61 group, the bufalin+cyclopamine group and the bufalin+GANT61+ cyclopamine group, respectively. The inhibitory effect of cell proliferation in the bufalin combining with Hh signaling pathway inhibitor group was significantly stronger than that of the bufalin group, especially the inhibitory effect in the bufalin+GANT61+cyclopamine group was strongest $(\mathrm{F}=27.777 ; \mathrm{P}=0.001, \mathrm{P}=0.026$ and $\mathrm{P}=0.006)$. It indicated that it could significantly enhance the inhibitory effect of bufalin on liver cancer cell proliferation after the key proteins of Hh signaling pathway such as Gli1 or Smo were inhibited. Bufalin had the strongest inhibitory effect on liver cancer cell proliferation when the key proteins of Gli1 and Smo in the $\mathrm{Hh}$ signaling pathway were simultaneously inhibited (Fig. 1).

Bufalin influences the cell cycle of HCC-LM3 cells. In our previous studies, it was shown that bufalin could block in $\mathrm{S}$ and G2 phase of HCC-LM3 cell proliferation, and the percentage of G1 phase cells was gradually decreased time and dose dependently (15). Therefore, we only observed the G1 phase and G2+S phase of cell cycle in the present study. The results showed that the percentage of G1 phase cells in bufalin combining with Hh signaling pathway inhibitor groups was less than that of the bufalin group, especially the percentage of G1 phase cells was the lowest in the bufalin+GANT61+cyclopamine group. However, the percentage of $\mathrm{G} 2+\mathrm{S}$ phase cells indicated an opposite trend. The percentage of $\mathrm{G} 2+\mathrm{S}$ phase cells were $38.05 \pm 2.62,52.75 \pm 2.75,67.34 \pm 2.33,68.18 \pm 1.83$ and $69.76 \pm 8.42 \%$ in the control group, the bufalin group, the bufalin+GANT61 group, the bufalin+cyclopamine group and the bufalin+GANT61+cyclopamine group, respectively. The percentage of $\mathrm{G} 2+\mathrm{S}$ phase cells in bufalin combining with $\mathrm{Hh}$ signaling pathway inhibitor groups was significantly higher than that of the bufalin group $(\mathrm{F}=29.782, \mathrm{P}=0.002, \mathrm{P}=0.001$ and $\mathrm{P}=0.001)$. Therefore, it indicated that bufalin blocked $\mathrm{S}$ and $\mathrm{G} 2$ phase of HCC-LM3 cell proliferation after the key

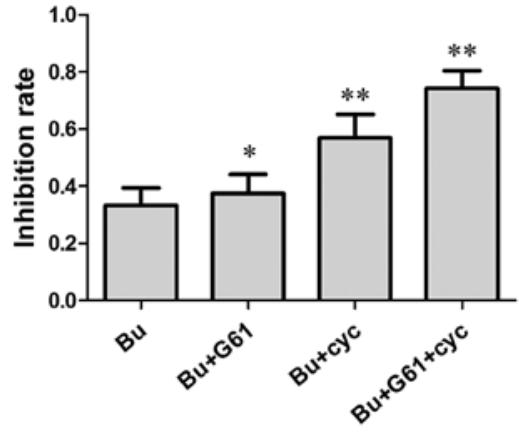

Figure 1. The influence of bufalin combining with Hedgehog signaling pathway inhibitors on the inhibition rate of cell growth in HCC-LM3 cells. The drug concentration of bufalin and Hedgehog signaling pathway inhibitors (cyclopamine, GANT61) was $0.000103,1$ and $5 \mu \mathrm{mol} / 1$, respectively. Bufalin and/or Hedgehog signaling pathway inhibitors was added into cell culture fluid for $72 \mathrm{~h}$ in vitro. The inhibition rates of cell growth were $33.68 \pm 8.38,38.28 \pm 8.33,58.30 \pm 9.08$ and $72.71 \pm 7.13 \%$ in the bufalin group, the bufalin+GANT61 group, the bufalin+cyclopamine group and the bufalin+GANT61+cyclopamine group, respectively. The results indicated that bufalin had the strongest inhibitory effect on cell proliferation of liver cancer cells after the key proteins of Gli1 and Smo in the Hh signaling pathway were simultaneously inhibited. ${ }^{*} \mathrm{P}<0.05,{ }^{* *} \mathrm{P}<0.01$ vs bufalin group.

proteins in Hh signaling pathway were inhibited. Bufalin has the strongest blocking effect on HCC-LM3 cells proliferation when the key proteins such as Gli1 and Smo were simultaneously inhibited (Fig. 2).

Bufalin induces apoptosis of HCC-LM3 cells. The results showed that the apoptotic rates of HCC-LM3 cells were $17.72 \pm 7.34,47.26 \pm 2.64,59.91 \pm 2.77,66.51 \pm 4.50$ and $76.77 \pm 4.05 \%$ in the control group, the bufalin group, the bufalin+GANT61 group, the bufalin+cyclopamine group and the bufalin+GANT61+cyclopamine group, respectively. The apoptotic ratio of HCC-LM3 cells was highest in the bufalin+GANT61+cyclopamine group than that of the bufalin group, the bufalin+GANT61 group and the bufalin+cyclopamine group $(\mathrm{F}=110.696, \mathrm{P}=0.002, \mathrm{P}=0.000$ and $\mathrm{P}=0.010$ ). It indicated that bufalin could induce apoptosis of HCC-LM3 cells, and the key inhibitors of Hh signaling pathway enhanced the apoptotic effect of bufalin alone when combining with GANT61 or cyclopamine (Fig. 3).

Bufalin inhibits migration of HCC-LM3 cells. Bufalin, alone or in combination with Hh signaling pathway inhibitors, inhibited migration of HCC-LM3 cells. However, the migrating rates of HCC-LM3 cells decreased significantly when HCC-LM3 cells were treated with bufalin combined with GANT61 or cyclopamine, the migrating rate was $65.08 \pm 3.31,42.75 \pm 0.97$ and $34.34 \pm 5.36 \%$ in the bufalin group, the bufalin+GANT61 group and the bufalin+GANT61+cyclopamine group, respectively. Besides, the migrating rate of HCC-LM3 cells in the bufalin+cyclopamine group was lower than that of the bufalin+GANT61 group $(\mathrm{F}=181.230, \mathrm{P}=0.001)$. Compared with the other groups, the migrating rate of HCC-LM3 cells was lowest in the bufalin+GANT61+cyclopamine group $(15.13 \pm 3.81 \%, F=181.230, P=0.003)$. It indicated that bufalin was able to inhibit migration of HCC-LM3 cells, and the Hh signaling pathway inhibitors enhanced the inhibitory effect 


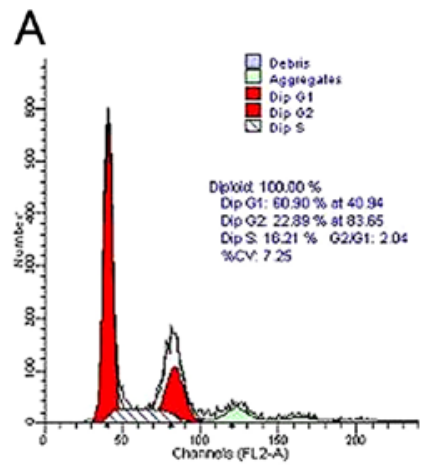

Control
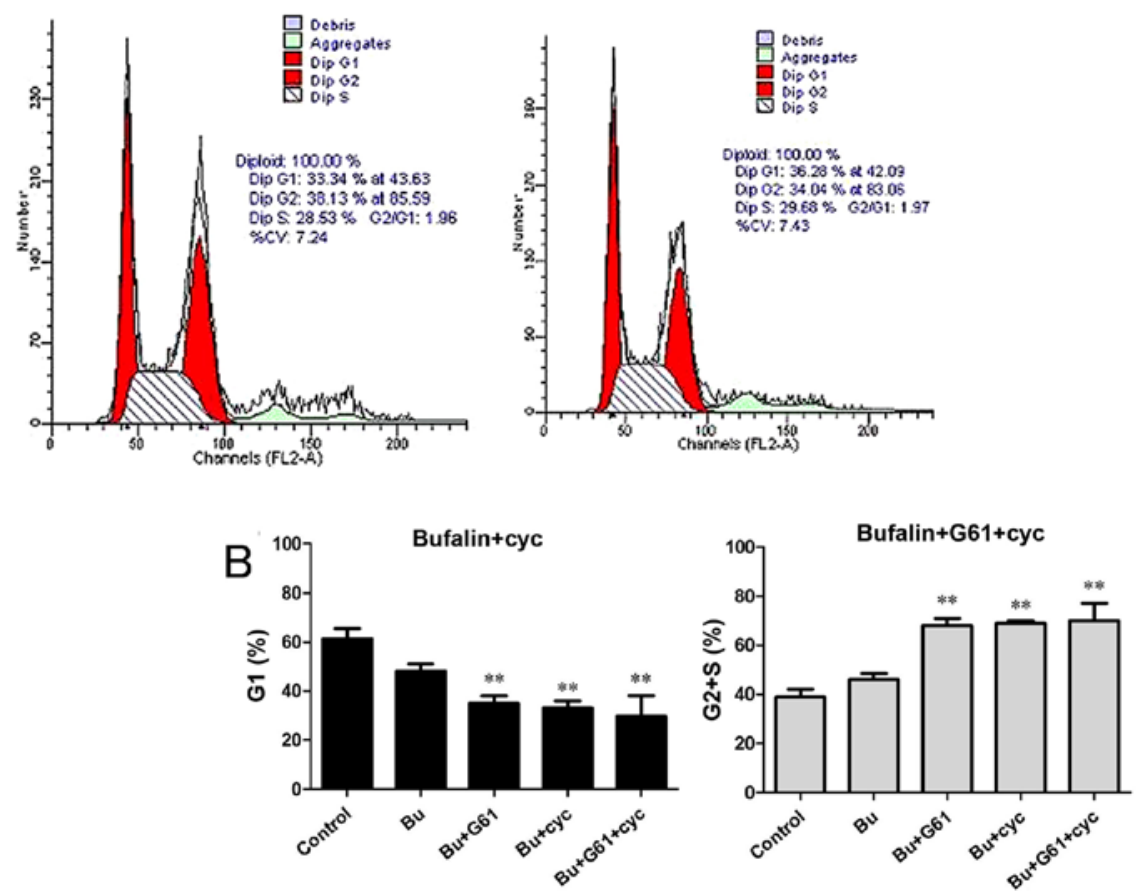

Figure 2. The influence of bufalin combined with Hedgehog signaling pathway inhibitors on the cell division cycle in HCC-LM3 cells. The drug concentration of bufalin and Hedgehog signaling pathway inhibitors (cyclopamine, GANT61) was 0.000103, 1 and $5 \mu \mathrm{mol} / 1$, respectively. Bufalin and/or Hedgehog signaling pathway inhibitors was added into cell culture fluid for $72 \mathrm{~h}$ in vitro. (A) The percentage of cells in the G1, S and G2 phases of the cell cycle was determined by flow cytometry. The percentage of $\mathrm{G} 2+\mathrm{S}$ phase cells in the control group, the bufalin group, the bufalin+GANT61 group, the bufalin+cyclopamine group and the bufalin+GANT61+cyclopamine group were $38.05 \pm 2.62,52.75 \pm 2.75,67.34 \pm 2.33,68.18 \pm 1.83$ and $69.76 \pm 8.42 \%$, respectively. (B) The percentage of G1 phase cells in bufalin combining with Hh signaling pathway inhibitor groups was less than that of the bufalin group, especially the percentage of G1 phase cells was the lowest in the bufalin+GANT61+cyclopamine group. The percentage of $\mathrm{G} 2+\mathrm{S}$ phase cells in bufalin combining with Hh signaling pathway inhibitor groups was significantly higher than that of bufalin group. Bufalin has the strongest blocking effect on HCC-LM3 cells proliferation when the key proteins such as Gli1 and Smo are simultaneously inhibited. ${ }^{* *} \mathrm{P}<0.01$ vs. bufalin group.

of bufalin, the synergetic effect was closely relative to the blocked site (Fig. 4).

Bufalin inhibits invasion of HCC-LM3 cells. After HCC-LM3 cells were exposed to bufalin with or Hh signaling pathway inhibitors for $72 \mathrm{~h}$, the results showed that the invading rates of HCC-LM3 cells were $49.77 \pm 13.6,33.48 \pm 2.2$, $27.73 \pm 6.98$ and $16.96 \pm 6.95 \%$ in the bufalin group, the bufalin+GANT61 group, the bufalin+cyclopamine group and the bufalin+GANT61+cyclopamine group, respectively. The invading rate of HCC-LM3 cells in the bufalin group was higher than that of the other groups $(\mathrm{F}=15.694$, $\mathrm{P}=0.003, \mathrm{P}=0.000$ and $\mathrm{P}=0.000)$. The invading rate of the bufalin+GANT61 group was 1.21 times higher than that of the bufalin+cyclopamine group $(\mathrm{F}=15.694, \mathrm{P}=0.001)$. Therefore, bufalin is able to inhibit invasion of HCC-LM3 cells, and Hh signaling pathway inhibitors enhanced the inhibitory effect of bufalin, the synergetic effect was also closely relative to the blocked site (Fig. 5).

Bufalin inhibits adhesion of HCC-LM3 cells. After HCC-LM3 cells were exposed to bufalin or with $\mathrm{Hh}$ signaling pathway inhibitors for $72 \mathrm{~h}$, the adhesive rates of HCC-LM3 cells were 73.92 $\pm 6.67,47.02 \pm 6.26$, $33.86 \pm 5.58$ and $20.91 \pm 3.44 \%$ in the bufalin group, the bufalin+GANT61 group, the bufalin+cyclopamine group and the bufalin+GANT61+cyclopamine group, respectively. Compared with the other groups, the adhesive rate of HCC-LM3 cells was the lowest in the bufalin+GANT61+cyclopamine group $(\mathrm{F}=48.636, \mathrm{P}=0.000$, 


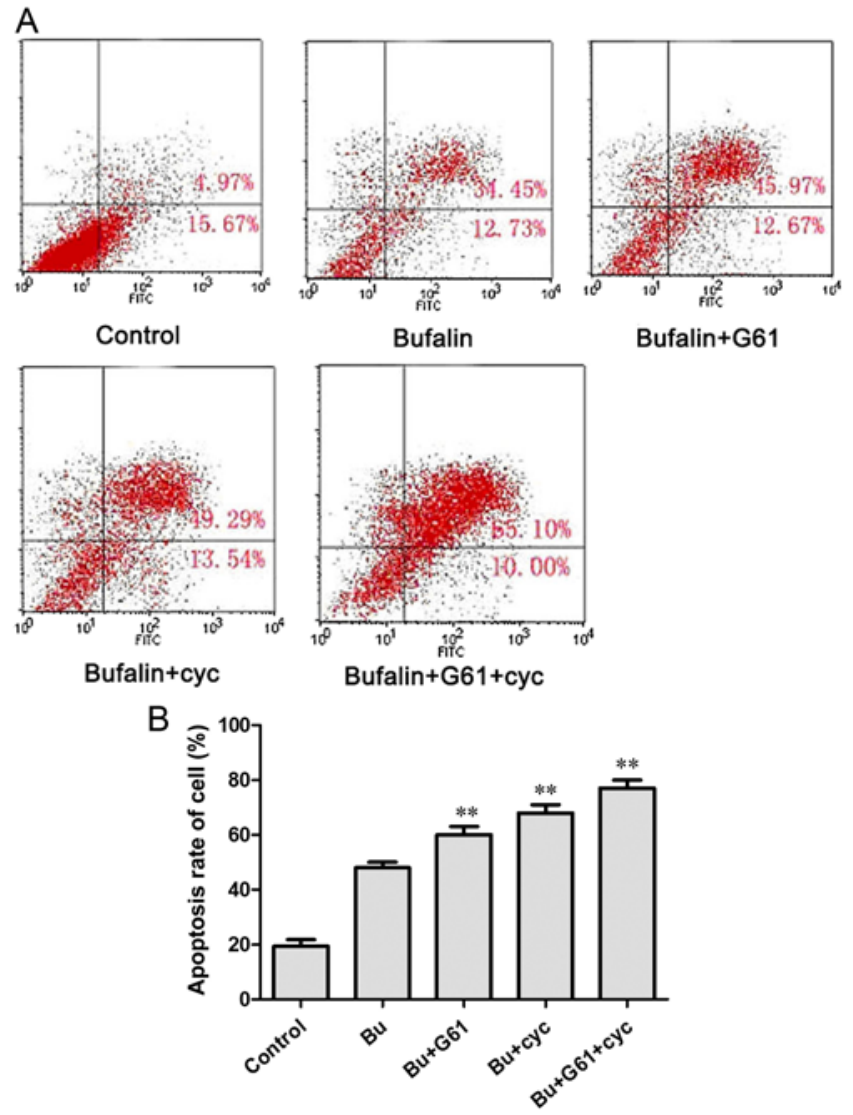

Figure 3. The influence of bufalin combined with Hedgehog signaling pathway inhibitors on the cell apoptosis in HCC-LM3 cells. The drug concentration of bufalin and Hedgehog signaling pathway inhibitors (cyclopamine, GANT61) was $0.000103,1$ and $5 \mu \mathrm{mol} / 1$, respectively. Bufalin and/or Hedgehog signaling pathway inhibitors was added into cell culture fluid for $72 \mathrm{~h}$ in vitro. (A) The percentage of aopototic cells was determined by flow cytometry. The apoptotic rates of HCC-LM3 cells in the control group, the bufalin group, the bufalin+GANT61 group, the bufalin+cyclopamine group and the bufalin+GANT61+cyclopamine group were $17.72 \pm 7.34,47.26 \pm 2.64$, $59.91 \pm 2.77,66.51 \pm 4.50$ and $76.77 \pm 4.05 \%$, respectively. (B) The apoptotic ratio of HCC-LM3 cells was highest in the bufalin+GANT61+cyclopamine group than that of in the bufalin group, the bufalin+GANT61 group and the bufalin+cyclopamine group. The key inhibitors of Hh signaling pathway enhanced the apoptotic effect of bufalin alone when combining with GANT61 or cyclopamine. ${ }^{* *} \mathrm{P}<0.01$, vs. bufalin group.

$\mathrm{P}=0.000$ and $\mathrm{P}=0.000$ ). The adhesive rate of HCC-LM3 cells in the bufalin+cyclopamine group was lower than that of the bufalin+GANT61 group $(\mathrm{F}=48.636, \mathrm{P}=0.021)$. It indicated that bufalin could inhibit the adhesion of HCC-LM3 cells, and Hh signaling pathway inhibitors enhanced the inhibitory effect of bufalin, the synergetic effect of cyclopamine was stronger than that of GANT61 (Fig. 6).

Bufalin influences the key protein expression of Hh signaling pathway in HCC-LM3 cells. After HCC-LM3 cells were exposed to bufalin or with Hh signaling pathway inhibitors for $72 \mathrm{~h}$, the results showed that there was no significant difference of $\mathrm{SHH}$ protein expression in various groups $(\mathrm{F}=0.309$, $\mathrm{P}>0.05)$.

Bufalin with or Hh signaling pathway inhibitors could inhibit the Ptch1 expression of HCC-LM3 cells (vs. control group, $\mathrm{F}=68.736, \mathrm{P}=0.037)$. There was no significant difference of the Ptch1 expression in HCC-LM3 cells between the
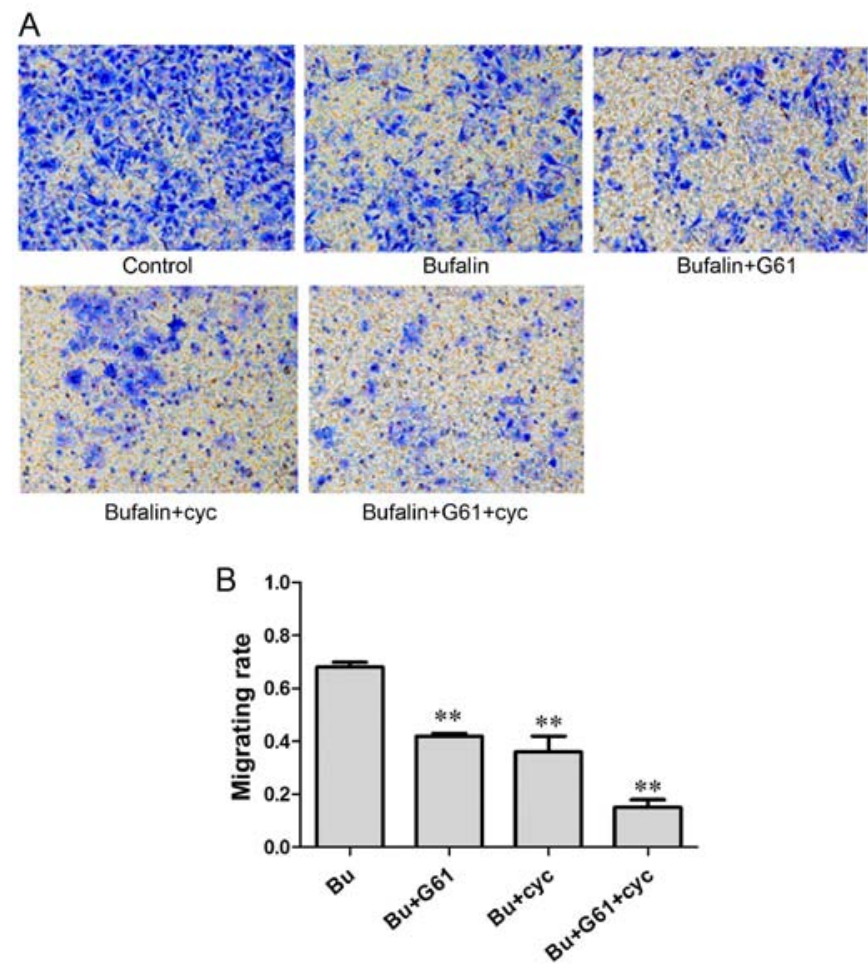

Figure 4. The influence of bufalin combined with Hedgehog signaling pathway inhibitors on the cell migration in HCC-LM3 cells. The drug concentration of bufalin and Hedgehog signaling pathway inhibitors (cyclopamine, GANT61) was $0.000103,1$ and $5 \mu \mathrm{mol} / 1$, respectively. Bufalin and/ or Hedgehog signaling pathway inhibitors was added into cell culture fluid for $72 \mathrm{~h}$ in vitro. (A) The cell migration assay was analyzed in a Transwell permeable support system. The number of migrated cells decreased gradually when bufalin was combined with GANT61 or cyclopamine (bluecolored cells; magnification, x200). (B) The migrating rate was $65.08 \pm 3.31$, $42.75 \pm 0.97$ and $34.34 \pm 5.36 \%$, respectively, in the bufalin+GANT61 group, the bufalin+cyclopamine group and the bufalin+cyclopamine group. The Hh signaling pathway inhibitors enhanced the inhibitory effect of bufalin, the synergetic effect was closely relative to the blocked site. ${ }^{* *} \mathrm{P}<0.01$ vs. bufalin group.

bufalin group and the bufalin+GANT61 group $(\mathrm{F}=68.736$, $\mathrm{P}>0.05)$. Bufalin combined with cyclopamine significantly inhibited the Ptch1 protein expression of HCC-LM3 cells (vs. bufalin group, $\mathrm{F}=68.736, \mathrm{P}=0.000)$. The results showed that bufalin could downregulate the Ptch1 protein expression of HCC-LM3 cells. Cyclopamine synergistically enhanced the inhibitory effect of bufalin.

Bufalin combined with GANT61 or cyclopamine significantly inhibited the Gli1 expression of HCC-LM3 cells (vs. bufalin group, $\mathrm{F}=7.45, \mathrm{P}=0.027, \mathrm{P}=0.001$ ). There was significant difference of the Gli1 expression in HCC-LM3 cells between the bufalin+GANT61 group and the bufalin+cyclopamine group $(\mathrm{F}=7.475, \mathrm{P}<0.05)$.

Bufalin was able to downregulate the Gli3 expression of HCC-LM3 cells, but there was no signifincant difference of the Gli3 expression between the bufalin group and the bufalin+GANT61 group $(\mathrm{F}=20.761, \mathrm{P}>0.05)$. Compared with the bufalin+GANT61, bufalin combined with cyclopamine could synergistically inhibit the Gli3 expression of HCC-LM3 cells $(\mathrm{F}=20.761 ; \mathrm{P}=0.026)$. Therefore, blocking the Smo protein could enhance the inhibitory effect of bufalin on the Gli3 expression in HCC-LM3 cells (Fig. 7). 

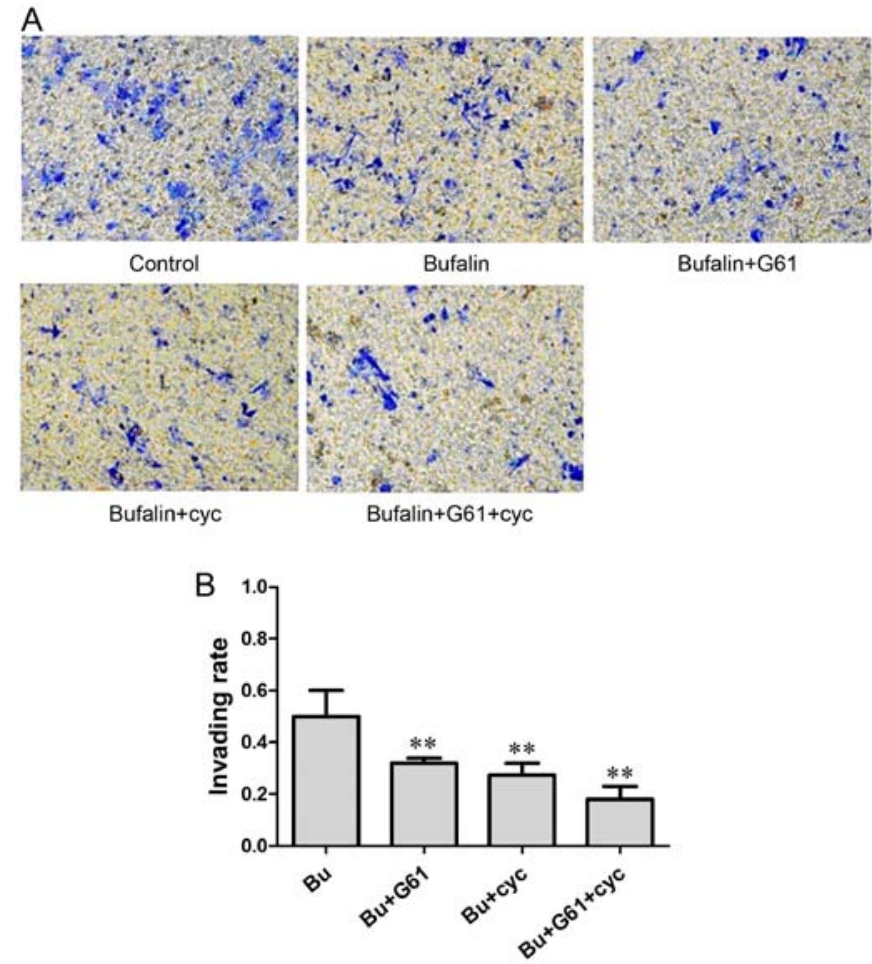

Figure 5. The influence of bufalin combined with Hedgehog signaling pathway inhibitors on the cell invasion in HCC-LM3 cells. The drug concentration of bufalin and Hedgehog signaling pathway inhibitors (cyclopamine, GANT61) was $0.000103,1$ and $5 \mu \mathrm{mol} / 1$, respectively. Bufalin and/or Hedgehog signaling pathway inhibitors was added into cell culture fluid for $72 \mathrm{~h}$ in vitro. (A) The cell invasion assay was analyzed in a Transwell permeable support system. The number of invaded cells decreased gradually when bufalin was combined with GANT61 or/and cyclopamine (blue-colored cells; magnification, x200). (B) The invading rates of HCC-LM3 cells in the bufalin group, the bufalin+GANT61 group, the bufalin+cyclopamine group and the bufalin+GANT61+cyclopamine group were $49.77 \pm 13.6,33.48 \pm 2.2,27.73 \pm 6.98$ and $16.96 \pm 6.95 \%$, respectively. Bufalin inhibited invasion of HCC-LM3 cells, and Hh signaling pathway inhibitors could enhance the inhibitory effect of bufalin. ${ }^{* *} \mathrm{P}<0.01$ vs. bufalin group.

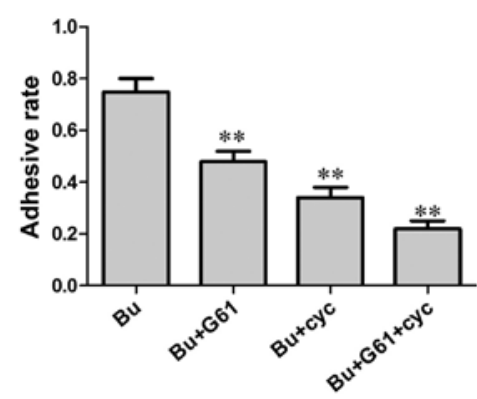

Figure 6. The influence of bufalin combined with Hedgehog signaling pathway inhibitors on the cell adhesion in HCC-LM3 cells. The drug concentration of bufalin and Hedgehog signaling pathway inhibitors (cyclopamine, GANT61) was $0.000103,1$ and $5 \mu \mathrm{mol} / 1$, respectively. Bufalin and/or Hedgehog signaling pathway inhibitors was added into cell culture fluid for $72 \mathrm{~h}$ in vitro. The cell adhesion assay was analyzed in a flat-bottomed plates containing DMEM-diluted Matrigel. The adhesive rates of HCC-LM3 cells in the bufalin group, the bufalin+GANT61 group, the bufalin+cyclopamine group and the bufalin+GANT61+cyclopamine group were $73.92 \pm 6.67,47.02 \pm 6.26,33.86 \pm 5.58$ and $20.91 \pm 3.44 \%$, respectively. Bufalin inhibited the adhesion of HCC-LM3 cells, and Hh signaling pathway inhibitors were able to enhance the inhibitory effect of bufalin, the synergetic effect of cyclopamine was stronger than that of GANT61. ${ }^{* *} \mathrm{P}<0.01$ vs. bufalin group.

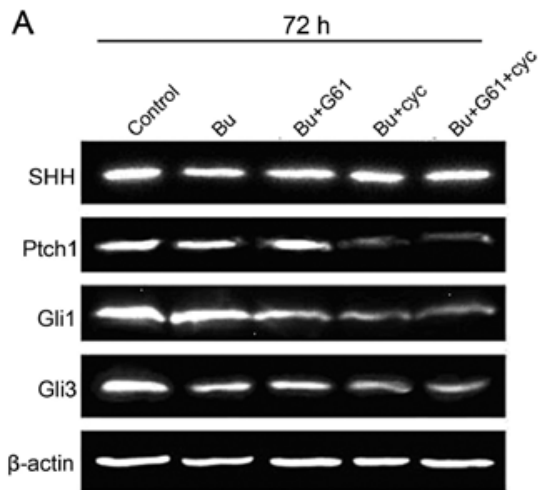

B
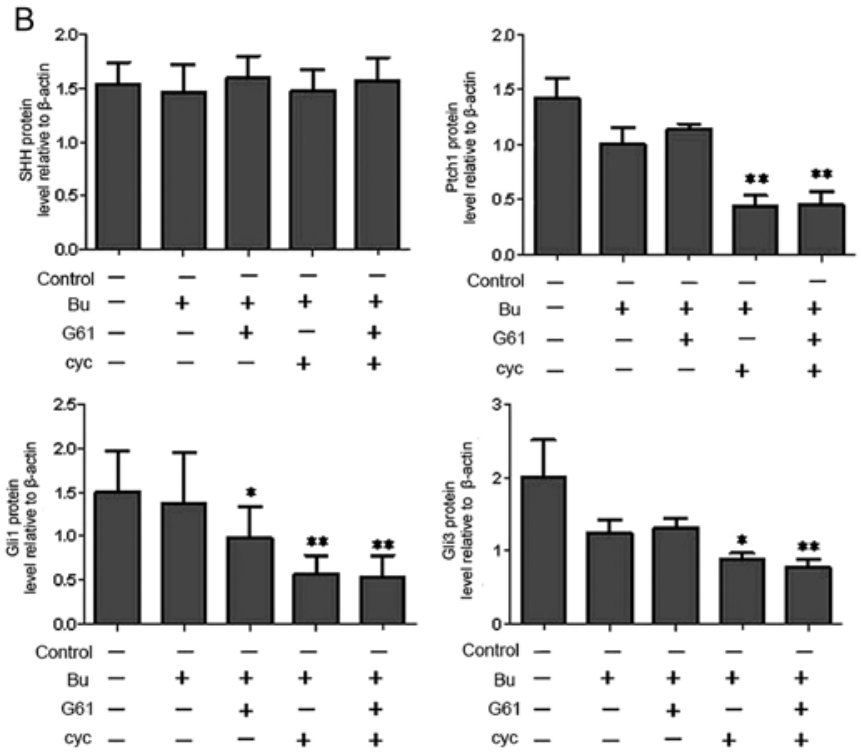

Figure 7. The influence of bufalin on the expression of key proteins of Hedgehog signaling pathway in HCC-LM3 cells. The drug concentration of bufalin and Hedgehog signaling pathway inhibitors (cyclopamine, GANT61) was $0.000103,1$ and $5 \mu \mathrm{mol} / 1$, respectively. Bufalin and/or Hedgehog signaling pathway inhibitors was added into cell culture fluid for $72 \mathrm{~h}$ in vitro. (A) The key proteins expression of Hedgehog signaling pathway in HCC-LM3 cells were determined by western blotting. The expression of the key proteins SHH, Ptch1, Gli1 and Gli3 in Hedgehog signaling pathway were displayed in the form of gel electrophoresis. $\beta$-actin was regarded as an internal reference. (B) The results indicated that bufalin with or the Hh signaling pathway inhibitors had not impact on the SHH protein expression in HCC-LM3 cells. Bufalin could downregulate the Ptch1 protein expression of HCC-LM3 cells. Cyclopamine could synergistically enhance the inhibitory effect of bufalin. Bufalin could significantly downregulate the Gli1 expression of HCC-LM3 cells by blocking Gli1 or Smo protein. Blocking the Smo protein enhanced the inhibitory effect of bufalin on the Gli3 expression in HCC-LM3 cells. ${ }^{*} \mathrm{P}<0.05,{ }^{* *} \mathrm{P}<0.01$ vs. bufalin group.

Bufalin influences the expression of downstream target proteins in Hh signaling pathway in HCC-LM3 cells. After HCC-LM3 cells were exposed to bufalin or with Hh signaling pathway inhibitors for $72 \mathrm{~h}$, the results showed that bufalin could downregulate the $\beta$-catenin expression of HCC-LM3 cells, and bufalin combined with GANT61 or cyclopamine could synergistically inhibit the $\beta$-catenin expression, especially bufalin combined with GANT61+cyclopamine had the strongest inhibitory effect on the $\beta$-catenin expression of HCC-LM3 cells $(\mathrm{F}=19.149, \mathrm{P}=0.000)$. However, there was no statistical difference of the $\beta$-catenin expression between the bufalin+GANT61 group and the bufalin+cyclopamine group $(\mathrm{F}=19.149, \mathrm{P}>0.05)$. 

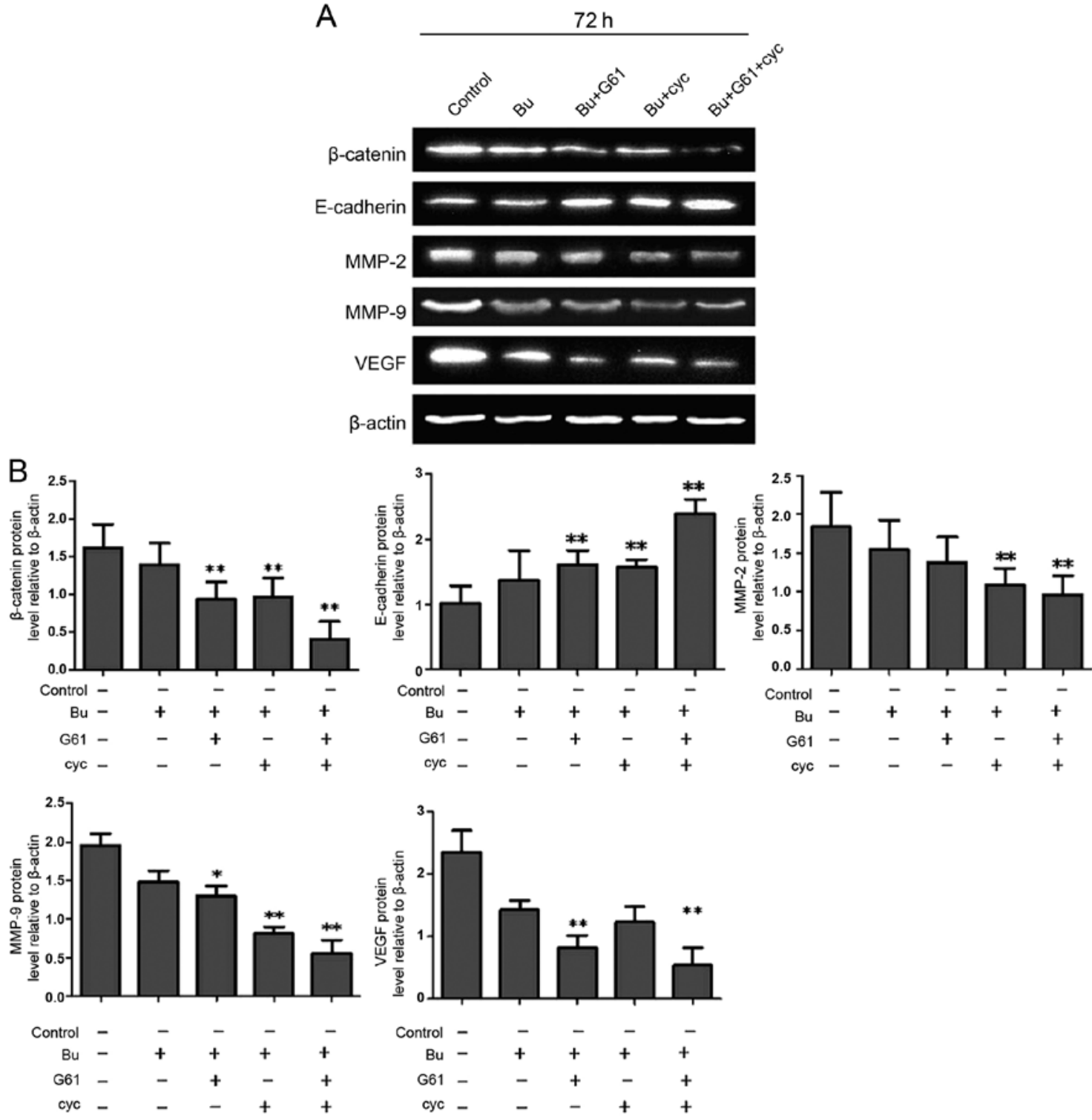

Figure 8. The influence of bufalin on the expression of invasive and metastatic proteins of Hedgehog signaling pathway in HCC-LM3 cells. The drug concentration of bufalin and Hedgehog signaling pathway inhibitors (cyclopamine, GANT61) was $0.000103,1$ and $5 \mu$ mol/l, respectively. Bufalin and/or Hedgehog signaling pathway inhibitors was added into cell culture fluid for $72 \mathrm{~h}$ in vitro. (A) The expression of invasive and metastatic proteins of Hedgehog signaling pathway in HCC-LM3 cells were determined by western blotting. The expression of invasive and metastatic proteins of $\beta$-catenin, E-cadherin, MMP-2, MMP-9 and VEGF in Hedgehog signaling pathway were displayed in the form of gel electrophoresis. $\beta$-actin was regarded as an internal reference. (B) The results showed that bufalin could downregulate the $\beta$-catenin, MMP-2, MMP-9 and VEGF expression in HCC-LM3 cells, and upregulate the E-cadherin expression in HCC-LM3 cells. Bufalin with GANT61+cyclopamine had the strongest synergistic effect on the $\beta$-catenin, E-cadherin, MMP-2, MMP-9 and VEGF expression in HCC-LM3 cells. The synergistic effect of Hedgehog signaling pathway inhibitors was closely related to the blocked site. It indicated that bufalin could inhibit the invasion and metastasis of HCC-LM3 cells by influencing the expression of key proteins in Hedgehog signaling pathway. "P<0.05, ${ }^{* *} \mathrm{P}<0.01$ vs. bufalin group.

Bufalin upregulated the E-cadherin expression of HCC-LM3 cells, and bufalin combined with GANT61 or cyclopamine could synergistically upregulate the E-cadherin expression, especially bufalin combined with GANT61+cyclopamine had the strongest upregulating effect on the E-cadherin expression of HCC-LM3 cells ( $\mathrm{F}=19.348$, $\mathrm{P}=0.000$ ). However, there was no statistical difference of the E-cadherin expression between the bufalin+GANT61 group and the bufalin+cyclopamine group $(\mathrm{F}=19.348, \mathrm{P}>0.05)$.

Bufalin could downregulate the MMP-2 expression of HCC-LM3 cells, and bufalin combined with GANT61 or cyclopamine synergistically downregulated the MMP-2 expression, especially bufalin with GANT61+cyclopamine had the strongest downregulating effect on the MMP-2 expression of HCC-LM3 cells ( $\mathrm{F}=10.913, \mathrm{P}=0.001)$. Moreover, there was a statistical difference of the MMP-2 expression between the bufalin+GANT61 group and the bufalin+cyclopamine group $(\mathrm{F}=10.913, \mathrm{P}=0.046)$.

Bufalin was able to downregulate the MMP-9 expression of HCC-LM3 cells, and bufalin combined with GANT61 or cyclopamine synergistically downregulated the MMP-9 expression, bufalin combined with GANT61+cyclopamine had the strongest downregulating effect on the MMP-9 expression of HCC-LM3 cells $(\mathrm{F}=93.588, \mathrm{P}=0.000)$. 


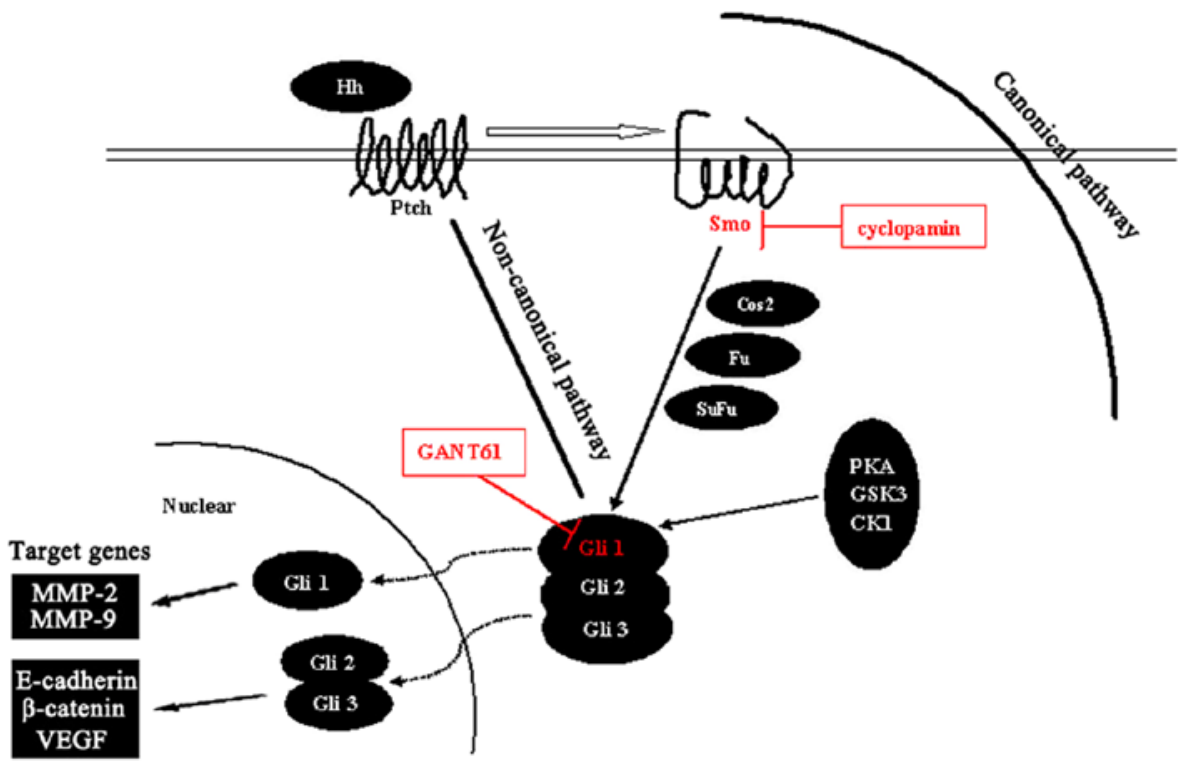

Figure 9. The regulation and control of bufalin on the invasive and metastatic molecules of liver cancer cells via Hh signaling pathway. The protein expression of Gli1 and Gli3 of liver cancer cells are regulated by the influence of bufalin on the key proteins of Ptch and Smo in Hh signaling pathway. The expression of MMP-2 and MMP-9 locates downstream of Gli1 regulated by the influence of bufalin on the Gli1 expression. The expression of $\beta$-catenin, E-cadherin and VEGF locates downstream of Gli3 and are regulated by the influence of bufalin on the Gli3 expression. It is an important mechanism of inhibition of the proliferation, invasion and metastasis of liver cancer cells by bufalin via Hh signaling pathway.

Moreover, the inhibitory effect of the MMP-9 expression in the bufalin+cyclopamine group was stronger than that of the bufalin+GANT61 group $(\mathrm{F}=93.588, \mathrm{P}=0.000)$.

Bufalin could significantly downregulate the VEGF expression of HCC-LM3 cells, and bufalin combined with GANT61 or cyclopamine could synergistically downregulate the VEGF expression of HCC-LM3 cells $(\mathrm{F}=28.787, \mathrm{P}=0.001)$. Moreover, the inhibitory effect on the VEGF expression in the bufalin+GANT61 group was stronger than that of the bufalin+cyclopamine group $(\mathrm{F}=28.787, \mathrm{P}=0.000)$. It showed that there was a better synergistic effect blocking Gli1 or Smo protein, it was closely related to the blocked site (Fig. 8).

\section{Discussion}

Invasion and metastasis of tumors, characteristic behavior of malignant tumors, is involved in multi-genes and multi-steps and is a complex pathological process. Tumor metastasis mostly begins of cancer cells after a large number of proliferation, then occur a series of pathological process such as matrix degradation, interstitial infiltration, tissue specificity chemotaxis, vascular invasion, capture for escaping cancer cells, choice for target organs, and the secondary proliferation in migrated site (10). Many signal transduction pathways, such as, MAPK, PI3K/AKT, Wnt, Hedgehog, Hippo, JAK/ STAT, TGF- $\beta$ and Notch, participate in tumor occurrence and development process, involving in tumor cell proliferation, apoptosis, differentiation and angiogenesis (20-24). Hedgehog signaling pathway is a highly conservative intercellular signal transduction system, which is composed of Hedgehog (Hh), Patched-Smoothened (Ptch-Smo), Glioma (Gli), Costal-2 (Cos2), Fuse (Fu), Suppressor of Fuse $(\mathrm{SuFu})$ and protein kinase A (PKA). Hh, Smo, Gli and Fu play positively regulatory roles in the process of Hh signal transduction. However, PTCH, Cos 2 and PKA, as inhibitory factors, play negative regulatory roles (25). After transcription factor Gli family are activated, Gli will transfer into the nucleus to regulate the Gli target gene expression. Therefore, many biological functions such as embryonic development, cellular self-renewal and angiogenesis can be maintained by regulating the target gene expression including CCND1, CCND2, VEGF, Snail, Wnts, Igf2, Bcl-2 and Bcl-XL via Hh signaling pathway (26).

GANT61, as a specific inhibitor for Gli1, can directly inhibit the transcription of Gli1. Kiesslich et al (27) found that GANT61 could effectively block the related molecular expression of Hh signaling pathway in bile duct cancer cells, induce cancer cells apoptosis, kill cancer cells and play an important antitumor role. Cyclopamine is a kind of nonsteroidal alkaloid, and extracted from a lily plant, which can block the molecular activation of Smo downstream by combining with the Smo protein. Because Hh signaling pathway occurs in the non-canonical path, of which the activation do not rely on Smo activity. When Smo activity is completely inhibited by cyclopamine, only Smo downstream of the canonical pathway can be blocked and the path is unaffected. Therefore, if GANT61 is chosen to completely inhibit the activity of Gli1, the canonical pathway and non-canonical bypass related with Glil can both be blocked (28). In addition, the neutralizing antibody for $\mathrm{SHH}$ was used to act on the different liver cancer cells (such as Hep3B, Huh7 and PLC/PRF/5), the results showed that the endogenous signal target gene expression of $\mathrm{Hh}$ signaling pathway decreased, and it promoted cancer cell apoptosis (29). The present study showed that bufalin could not influence the $\mathrm{SHH}$ protein expression of Hh signaling pathway, and there was no influence on the $\mathrm{SHH}$ protein expression by blocking the protein expression of Gli1 or Smo. Bufalin downregulated the Ptch1 protein expression, cyclopamine could cooperatively enhance the inhibitory effect of bufalin, but GANT61 could not. It 
indicated that bufalin inhibited the Ptch1 expression of liver cancer cells through Smo protein in Hh signaling pathway. Blocking the Gli1 or Smo protein could significantly enhance the inhibitory effect of bufalin on the Glil protein expression. Blocking the Smo protein not GANT61 could significantly enhance the inhibitory effect of bufalin on the Gli3 protein expression. It indicated that bufalin inhibited the Gli3 expression of liver cancer cells through Smo protein.

Once proliferation and apoptosis of the tumor cells is out of balance, cancer cells will excessively proliferate resulting in tumorigenesis. Tsai et al (30) confirmed that bufalin could block the cell cycle of SK-Hep-1 liver cancer cells in G2/M phase and downregulated the expression of cyclin A and cyclin B. Han et al (31) established the orthotopic transplantation model of liver cancer, then bufalin was used in vivo, the result showed that the tumor tissues had apoptotic signs, such as less cytoplasm, nuclear pyknosis, condensed chromatin edging and nuclear fragmentation. The scanning electron microscopy showed tumor cell shrinkage, condensed cytoplasm, chromatin gathered in nuclear membrane in the shape of mass or crescent, cytoplasm vacuoles and apoptotic bodies. In this study, the results showed that the inhibitory effect of bufalin on the proliferation of liver cancer cells was significantly enhanced when the key proteins of $\mathrm{Hh}$ signaling pathway, Gli1 or Smo, were blocked. The inhibitory effect of bufalin on the proliferation of liver cancer cells was the strongest when the Glil and Smo were simultaneously blocked. The percentage of HCC-LM3 cells in S and G2 phase significantly increased when the bufalin was combined with the Glil or Smo protein inhibitor. The results indicated that bufalin could induce cell apoptosis of HCC-LM3 cells, and Hh signaling pathway inhibitors could synergistically enhance the apoptogenic ability of bufalin.

Epithelial mesenchymal transition (EMT) is a biological process of which epithelial cells are lose polarity by specific program and obtain the characteristics of mesenchymal cells. The tumor cells of epithelial malignant tumors have powerful ability of local invasion and distant metastasis by EMT. Once the epithelial cells occur in mesenchymal transition, cell cytoskeleton rearrange, phenotype change, homogeneity adhesion ability reduce, and cells become looser to obtain invasion and metastasis ability. Normal epithelial cells do not exist widely in EMT process, the epithelial cells occur in EMT when the markers expression of epithelial cells downregulate, and the marker expression of mesenchymal cells upregulate. The downregulation of E-cadherin expression is the marker expression of epithelial cell downregulation. E-cadherin, $\mathrm{Ca}^{2+}$-dependent transmembrane glycoprotein, is one of the important members of the cadherin family, and mainly expressed in the membrane of mammal epithelial cells. E-cadherin can promote the adhesive reaction of the cells $(32,33)$. Once the E-cadherin expression downregulates the tumor cells, homogeneous adhesive ability of tumor cells will significantly weakened, and the tumor cells are prone to invasion and metastasis. $\beta$-catenin is a member of the link chain protein family, and mainly exists in the cell membrane and slightly in the cytoplasm. $\beta$-catenin can combine with more than 20 species of proteins to mediate intercellular adhesion. The spatial structure of E-cadherin consists of intracellular region, extracellular region and transmembrane region. A zipper-like space structure will be formed between the epithelial cells when $\beta$-catenin binding to E-cadherin extracellular region, the space structure is of great significance to maintain stable morphology of epithelial tissue (34-36). The present study showed that bufalin could inhibit the migration, invasion and adhesion of HCC-LM3 cells, and Hh signaling pathway inhibitors such as GANT61 or cyclopamine could strengthen the inhibitory ability of bufalin. The strongest inhibitory effect of bufalin was with combining with the two inhibitors on HCC-LM3 cells. Bufalin could upregulate the E-cadherin expression and downregulate the $\beta$-catenin expression in HCC-LM3 cells. GANT61 or cyclopamine could significantly enhance the regulating effect of bufalin, and the two Hh signaling pathway inhibitors synergistically enhanced the regulating effect of bufalin. It indicated that blocking the key proteins of Hh signaling pathway, Smo or Gli1, could significantly strengthen the inhibitory effect of bufalin on EMT of HCC-LM3 cells, and the inhibitory effect of bufalin on EMT was closely related with molecular sites of Hh signaling pathway in HCC-LM3 cells.

Extracellular matrix (ECM) degradation is an important contribution to the invasion and metastasis of tumors. There are complex components of ECM between a large number of mammalian cells, which are mainly composed of structural proteins, adhesion proteins, glycosaminoglycans and proteoglycans. Proteins and polysaccharides constitute macromolecules of ECM (37). Malignant cells can produce or induce protein degradation enzymes to destroy the structure of ECM, resulting in slow local dissolving and temporary channels of invasion and metastasis. Protein degradation enzymes usually include four categories: serine protease, metalloproteinases, elastic protease and cysteine protease. Metalloproteinases are very important factors to degrade the ECM among them. Matrix metalloproteinases (MMPs), of which $\mathrm{Ca}^{2+}, \mathrm{Zn}^{2+}$ and other metal ions are key cofactors of MMPs, degrading a variety of protein composition in ECM, and play a key role in the process of tumor invasion and metastasis. Under normal circumstances, the connective tissue, endothelial tissue and epithelial tissue can secrete the MMPs. Various MMPs have sequence homology in the form of inactive enzyme precursor. Tissue inhibitor of metalloproteinases (TIMPs) limit the activity of MMPs and maintain the stability in the ECM (38). Under the influence of various factors, once the balance of MMPs and TIMPs is broken, the ECM degradation occur (39). Chueh et al (40) found that bufalin may inhibit the MMP-2 expression by blocking the MAPK signal pathway and eventually reduce the ability of invasion and metastasis of osteosarcoma cells U-2. Chen et al (41) proved that bufalin inhibited the MMP-2 and MMP-9 activity and downregulated the PI3K/ AKT and $N F-\kappa B$ signaling pathways, then inhibited the invasion and metastasis ability of liver cancer SK-Hep1 cells. This study indicated that blocking Gli1 or Smo protein could significantly enhance the inhibitory effect bufalin on downregulating MMP-2 and MMP-9 protein expression in HCC-LM3 cells, especially blocking the Smo protein had a better synergistic effect than that of blocking Gli1 protein. Moreover, the two inhibitors together with bufalin had the strongest synergistic effect on downregulating MMP-2 and MMP-9 protein expression in HCC-LM3 cells. 
Angiogenesis plays a key role in the malignant tumor growth, invasion and metastasis process. The division and proliferation of vascular endothelial cells are the important material basis of tumor angiogenesis. After bufalin was added into human umbilical vascular endothelial cells ECV304 in vitro, Zhai et al (42) found that bufalin has significant inhibitory effect of vascular endothelial cells on proliferation and angiogenesis time and dose dependently. In addition, GDC-0449, an inhibitor of Hh signaling pathway, was selected to act on hepatoma cells, in vivo and in vitro experimental results showed that VEGF expression was downregulated in hepatocellular carcinoma, suggesting that Hh signaling pathway was directly related to angiogenesis in hepatocellular carcinoma (19). Our experimental results showed that bufalin could inhibit VEGF expression in HCC-LM3 cells, GANT61 or cyclopamine could synergistically enhance the inhibitory effect of bufalin, and GANT61 had a better synergistic effect than that of cyclopamine. Moreover, bufalin combining the two inhibitors had the best inhibitory effect on the VEGF expression in HCC-LM3 cells.

In conclusion, the present study shows that blocking the key proteins such as Glil or Smo in Hh signaling pathway can significantly enhance the inhibitory effect of bufalin on inhibiting the proliferation, invasion and metastasis of liver cancer cells. The revealed mechanism is that bufalin can inhibit the EMT, and ECM degradation and angiogenesis of liver cancer cells by influencing the expression of Ptch1, Gli1, Gli3 proteins in Hh signaling pathway. Bufalin can inhibit the downstream target molecules of MMP-2 and MMP-9 in liver cancer cells by influencing the Gli1 protein expression of Hh signaling pathway. Bufalin can upregulate the E-cadherin expression and downregulate the $\beta$-catenin and VEGF expressions of liver cancer cells by influencing the Gli3 protein expression of Hh signaling pathway. Bufalin combining with the inhibitors of Hh signaling pathway can significantly reduce malignant biological behavior of liver cancer cells via Hh signaling pathway (Fig. 9).

\section{Acknowledgements}

We thank Professor Zhaoyou Tang at the Fudan University for providing the HCC-LM3 cell line. The present study was supported by the Major Project of Science and Technology commission of Shanghai Putuo district (PT2012-B-162).

\section{References}

1. Martí-Bonmatí L, Sanz-Requena R, de Gracia BP and CarotSierra JM: Magnetic resonance pharmacokinetic imaging clusterization of hepatocellular carcinomas as a means to grade tumor aggressiveness. Expert Rev Gastroenterol Hepatol 6: 711-716, 2012.

2. Xiong JJ, Altaf K, Javed MA, Huang W, Mukherjee R, Mai G, Sutton R, Liu XB and Hu WM: Meta-analysis of laparoscopic vs open liver resection for hepatocellular carcinoma. World J Gastroenterol 18: 6657-6668, 2012.

3. Yoon AJ, Kuo WH, Lin CW and Yang SF: Role of ERCC5 polymorphism in risk of hepatocellular carcinoma. Oncol Lett 2: 911-914, 2011.

4. Cotoi CG, Khorsandi SE, Pleşea IE and Quaglia A: Histological aspects of post-TACE hepatocellular carcinoma. Rom J Morphol Embryol 53 (Suppl): 677-682, 2012.

5. Chen JG and Zhang SW: Liver cancer epidemic in China: Past, present and future. Semin Cancer Biol 21: 59-69, 2011.

6. Jang KY, Noh SJ, Lehwald N, Tao GZ, Bellovin DI, Park HS Moon WS, Felsher DW and Sylvester KG: SIRT1 and c-Myc promote liver tumor cell survival and predict poor survival of human hepatocellular carcinomas. PLoS One 7: e45119, 2012.
7. Sandhu DS, Tharayil VS, Lai JP and Roberts LR: Treatment options for hepatocellular carcinoma. Expert Rev Gastroenterol Hepatol 2: 81-92, 2008.

8. Zheng X, Gai X, Han S, Moser CD, Hu C, Shire AM, Floyd RA and Roberts LR: The human sulfatase 2 inhibitor 2,4-disulfonylphenyl-tert-butylnitrone (OKN-007) has an antitumor effect in hepatocellular carcinoma mediated via suppression of TGFB1/ SMAD2 and Hedgehog/GLI1 signaling. Genes Chromosomes Cancer 52: 225-236, 2013

9. Jemal A, Bray F, Center MM, Ferlay J, Ward E and Forman D: Global cancer statistics. CA Cancer J Clin 61: 69-90, 2011.

10. Woo HG, Park ES, Cheon JH, Kim JH, Lee JS, Park BJ, Kim W, Park SC, Chung YJ, Kim BG, et al: Gene expressionbased recurrence prediction of hepatitis B virus-related human hepatocellular carcinoma. Clin Cancer Res 14: 2056-2064, 2008.

11. Miao Q, Bi LL, Li X, Miao S, Zhang J, Zhang S, Yang Q, Xie YH, Zhang J and Wang SW: Anticancer effects of bufalin on human hepatocellular carcinoma HepG2 cells: Roles of apoptosis and autophagy. Int J Mol Sci 14: 1370-1382, 2013.

12. Li D, Qu X, Hou K, Zhang Y, Dong Q, Teng Y, Zhang J and Liu Y: PI3K/Akt is involved in bufalin-induced apoptosis in gastric cancer cells. Anticancer Drugs 20: 59-64, 2009.

13. Yin P, Wang Y, Qiu Y, Hou L, Liu X, Qin J, Duan Y, Liu P, Qiu M and Li Q: Bufalin-loaded mPEG-PLGA-PLL-cRGD nanoparticles: Preparation, cellular uptake, tissue distribution, and anticancer activity. Int J Nanomedicine 7: 3961-3969, 2012.

14. Han KQ, Huang G, Gu W, Su YH, Huang XQ and Ling CQ: Anti-tumor activities and apoptosis-regulated mechanisms of bufalin on the orthotopic transplantation tumor model of human hepatocellular carcinoma in nude mice. World $\mathbf{J}$ Gastroenterol 13: 3374-3379, 2007.

15. Gai JQ, Qin JM and Fan YZ: Experimental study on bufalin inhibiting hepatocellular carcinoma proliferation and invasion. World Chin J Digestology 22: 1921-1927, 2014.

16. Nüsslein-Volhard $\mathrm{C}$ and Wieschaus E: Mutations affecting segment number and polarity in Drosophila. Nature 287: 795-801, 1980.

17. Yoo YA, Kang MH, Kim JS and Oh SC: Sonic hedgehog signaling promotes motility and invasiveness of gastric cancer cells through TGF-beta-mediated activation of the ALK5-Smad 3 pathway. Carcinogenesis 29: 480-490, 2008.

18. Li X, Wang Z, Ma Q, Xu Q, Liu H, Duan W, Lei J, Ma J, Wang X, Lv S, et al: Sonic hedgehog paracrine signaling activates stromal cells to promote perineural invasion in pancreatic cancer. Clin Cancer Res 20: 4326-4338, 2014.

19. Pinter M, Sieghart W, Schmid M, Dauser B, Prager G, Dienes HP, Trauner $M$ and Peck-Radosavljevic M: Hedgehog inhibition reduces angiogenesis by downregulation of tumoral VEGF-A expression in hepatocellular carcinoma. United European Gastroenterol J 1: 265-275, 2013.

20. Yang J, Zeng Z, Peng Y, Chen J, Pan L and Pan D: IL-7 splicing variant IL-7 $\delta 5$ induces EMT and metastasis of human breast cancer cell lines MCF-7 and BT-20 through activation of PI3K/ Akt pathway. Histochem Cell Biol 142: 401-410, 2014.

21. Li R, Liu J, Wu H, Liu L, Wang L and Zhang S: TIKI2 suppresses growth of osteosarcoma by targeting Wnt/ $\beta$-catenin pathway. Mol Cell Biochem 392: 109-116, 2014.

22. Yue D, Li H, Che J, Zhang Y, Tseng HH, Jin JQ, Luh TM, Giroux-Leprieur E, Mo M, Zheng Q, et al: Hedgehog/Gli promotes epithelial-mesenchymal transition in lung squamous cell carcinomas. J Exp Clin Cancer Res 33: 34, 2014.

23. Pratt $\mathbf{J}$ and Annabi B: Induction of autophagy biomarker BNIP3 requires a JAK2/STAT3 and MT1-MMP signaling interplay in Concanavalin-A-activated U87 glioblastoma cells. Cell Signal 26: 917-924, 2014.

24. Wu L, Herman JG, Brock MV, Wu K, Mao G, Yan W, Nie Y, Liang $\mathrm{H}$, Zhan $\mathrm{Q}$, Li W, et al: Silencing DACH1 promotes esophageal cancer growth by inhibiting TGF- $\beta$ signaling. PLoS One 9: e95509, 2014.

25. Hui CC and Angers S: Gli proteins in development and disease. Annu Rev Cell Dev Biol 27: 513-537, 2011.

26. Cheng SY and Yue S: Role and regulation of human tumor suppressor SUFU in Hedgehog signaling. Adv Cancer Res 101: 29-43, 2008.

27. Kiesslich T, Mayr C, Wachter J, Bach D, Fuereder J, Wagner A, Alinger B, Pichler M, Di Fazio P, Ocker M, et al: Activated hedgehog pathway is a potential target for pharmacological intervention in biliary tract cancer. Mol Cell Biochem 396: 257-268, 2014. 
28. Li X, Ma Q, Xu Q, Liu H, Lei J, Duan W, Bhat K, Wang F, Wu E and Wang Z: SDF-1/CXCR4 signaling induces pancreatic cancer cell invasion and epithelial-mesenchymal transition in vitro through non-canonical activation of Hedgehog pathway. Cancer Lett 322: 169-176, 2012.

29. Huang S, He J, Zhang X, Bian Y, Yang L, Xie G, Zhang K, Tang W, Stelter AA, Wang Q, et al: Activation of the hedgehog pathway in human hepatocellular carcinomas. Carcinogenesis 27: 1334-1340, 2006.

30. Tsai SC, Yang JS, Peng SF, Lu CC, Chiang JH, Chung JG, Lin MW, Lin JK, Amagaya S, Wai-Shan Chung C, et al: Bufalin increases sensitivity to AKT/mTOR-induced autophagic cell death in SK-HEP-1 human hepatocellular carcinoma cells. Int J Oncol 41: 1431-1442, 2012.

31. Han KQ, Gu W, Su YH, Huang XQ, Wang X and Ling CQ: Overall pharmacodynamic study of Bufalin anti-mouse orthotopic liver transplantation. Chin J Exp Surg 21: 1436-1438, 2004.

32. Roxanis I: Occurrence and significance of epithelial-mesenchymal transition in breast cancer. J Clin Pathol 66: 517-521, 2013.

33. Debruyne P, Vermeulen S and Mareel M: The role of the E-cadherin/catenin complex in gastrointestinal cancer. Acta Gastroenterol Belg 62: 393-402, 1999.

34. Scanlon CS, Van Tubergen EA, Inglehart RC and D'Silva NJ: Biomarkers of epithelial-mesenchymal transition in squamous cell carcinoma. J Dent Res 92: 114-121, 2013.

35. Cervantes-Arias A, Pang LY and Argyle DJ: Epithelialmesenchymal transition as a fundamental mechanism underlying the cancer phenotype. Vet Comp Oncol 11: 169-184, 2013.

36. Shapiro L and Weis WI: Structure and biochemistry of cadherins and catenins. Cold Spring Harb Perspect Biol 1: a003053, 2009.
37. Jerrell RJ and Parekh A: Cellular traction stresses mediate extracellular matrix degradation by invadopodia. Acta Biomater 10: 1886-1896, 2014

38. Nielsen HJ, Brünner N, Frederiksen C, Lomholt AF, King D, Jørgensen LN, Olsen J, Rahr HB, Thygesen K, Hoyer U, et al; Danish Colorectal Cancer Cooperative Group: Plasma tissue inhibitor of metalloproteinases-1 (TIMP-1): A novel biological marker in the detection of primary colorectal cancer. Protocol outlines of the Danish-Australian endoscopy study group on colorectal cancer detection. Scand J Gastroenterol 43: 242-248, 2008.

39. Zucker S, Doshi K and Cao J: Measurement of matrix metalloproteinases (MMPs) and tissue inhibitors of metalloproteinases (TIMP) in blood and urine: Potential clinical applications. Adv Clin Chem 38: 37-85, 2004.

40. Chueh FS, Chen YY, Huang AC, Ho HC, Liao CL, Yang JS, Kuo CL and Chung JG: Bufalin-inhibited migration and invasion in human osteosarcoma U-2 OS cells is carried out by suppression of the matrix metalloproteinase-2, ERK, and JNK signaling pathways. Environ Toxicol 29: 21-29, 2014

41. Chen YY, Lu HF, Hsu SC, Kuo CL, Chang SJ, Lin JJ, Wu PP, Liu JY, Lee CH, Chung JG, et al: Bufalin inhibits migration and invasion in human hepatocellular carcinoma SK-Hep1 cells through the inhibitions of NF- $\kappa \mathrm{B}$ and matrix metalloproteinase2/-9-signaling pathways. Environ Toxicol 30: 74-82, 2015.

42. Zhai XF, Lv X, Gu W, Song CC and Li B: Three kinds of antitumor Chinese medicine effective components influencing on human umbilical vein endothelial cells growth. Chin Remedics Clin 11: 752-754, 2011. 